\title{
Calibration of Dial Indicator Using Calibration Tester with JIS B 7503 Standard
}

\author{
Dodi Sofyan Arief ${ }^{a, *}$, Amir Pahlevi a ${ }^{a}$ Agus Surya Permana ${ }^{b}$ \\ a) Mechanical Engineering Department, Universitas Riau, Indonesia \\ b) Balai Besar Bahan dan Barang Teknik, Jl. Sangkuriang No.14 Bandung 40135 Jawa Barat, Indonesia
}

*Corresponding author: dodidarul@yahoo.com

\section{Paper History}

Received: 03-June-2021

Received in revised form: 17-June-2021

Accepted: 30-July-2021

\section{ABSTRACT}

The measurement process is the most important part of the production process in the industrial world. Obtaining good measurement results can not be separated from using measuring instruments that are always maintained. Subsequence, the maintenance of calibration procedures must be carried out periodically based on a predetermined time limit The calibration process is an activity to compare standard quantities between measuring instruments and testers that are in accordance with the measuring instrument and carried out periodically. The implementation of the calibration process often has generates an uneven value where this value is better known as the uncertainty value. This research objective is to determine the uncertainty value of the measuring instrument of a dial indicator using the JIS B 7503 Standard. The calibration can control the quality of the equipment used, and can show whether the tool is feasible or not to be used.
\end{abstract}

KEY WORDS: Calibration, Dial indicator, Calibration tester.

\subsection{INTRODUCTION}

The development of technology and the global market has got faster and it necessary to have standards that regulate goods and services. The purpose of providing and using the standard is due to none other than the safety and suitability of a product being used. The conformity assessment of a product often includes a measured value, which is located close to the uncertainty zone. Differences in uncertainty evaluation method between producer and consumer countries can lead to rejection of an international trade commodity due to differences in the results of the calculation of uncertainty [1].

The measurement results has being inaccurate include the source of the measuring object, measuring standards, calibration technicians, measurement environment and measurement methods [1]. Implementation of Standard Operating Procedures (SOP) for the measurement process and correct calibration gives a result of a good standard.

The use of dial indicators as comparative measuring tools has been needed in the industrial world and the academic world in laboratories and engineering workshops to requiring careful and precise dimensions. One of the requirements of the calibration system is that every piece of equipment that has a measuring value that is required to be calibrated with a standard tool, which in this case uses a calibration tester. From the results of this calibration, it can find out the error value of the dial indicator. In this research aims to determine the uncertainty value of the measuring instrument of a dial indicator using the JIS B 7503 Standard.

\subsection{LITERATURE REVIEW}

\subsection{Calibration}

Calibration is set of operations that establish, under specified conditions, the relationship between values of quantities indicated by a measuring instrument or measuring system, or values represented by a material measure or a reference material, and the corresponding values realized by standards [2]. According to ISO/IEC Guide 17025 and Vocabulary of International Metrology (VIM) are following [2]:

NOTE 1: The result of a calibration permits either the assignment of values of measurands to the indications or the determination of corrections with respect to indications.

NOTE 2: A calibration may also determine other metrological properties such as the effect of influence quantities.

NOTE 3: The result of a calibration may be recorded in a document, sometimes called a calibration certificate or a calibration report. 
In other words, calibration is an activity to determine the conventional truth of the value of the indication of measuring instruments and measuring materials by comparing them to traceable measuring standards to national and/or international standards for units of measure [2]. Definition of calibration based on KAN, calibration is an activity that under certain conditions, in the first stage, establishes a relationship between the value of the quantity and the measurement uncertainty given by the measurement standard and the designation associated with its measurement uncertainty, and in the second stage, uses this information to establish a relationship to obtain measurement results based on a reference [3].

Every measuring instrument before or after being used for a certain period (6 months or 12 months), must be calibrated according to national or international standards. Measuring instruments are the spearhead in the quality of the products produced because they are directly related to the process, so they need to be maintained to get a long lifetime [4-6].

\subsection{Dial Indicators}

Dial indicator is a comparative measuring tool that is widely used in the machinery industry in the production section, and in the measurement section. The working principle is mechanical, where the linear motion of the sensor is converted into a circular motion of the pointer on a scaled disk by means of teeth and gear arrangements. The coil spring functions as a toothed rod suppressor so that the sensor always presses down. The spiral spring functions as a suppressor of the gear transmission system so that the paired tooth surfaces always press on the same side for both directions of rotation to avoid black-lash that may occur due to an imperfect tooth profile or due to wear [7-8] as shown in Figure 1
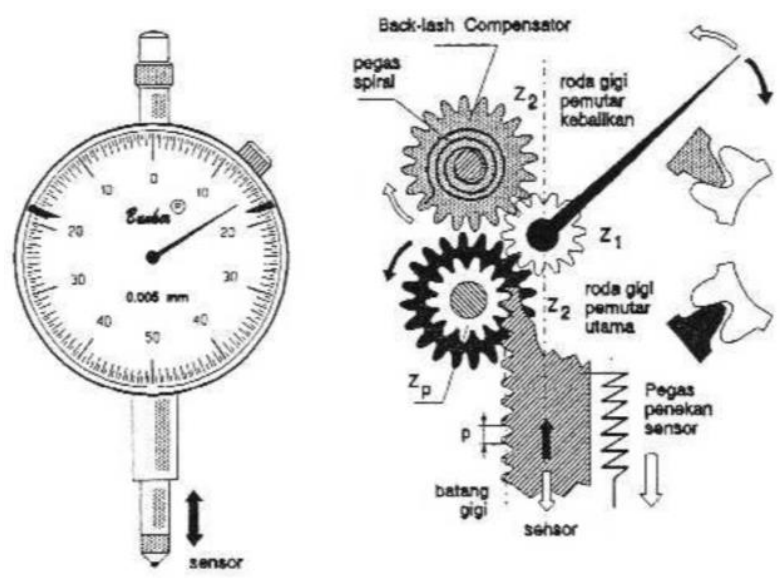

Figure 1: The principle of a mechanical modifier is applied to a dial indicator [7-8]

The accuracy of the scale reading is $0.01,0.005$, or 0.002 $\mathrm{mm}$ with various measuring certainty, for example, 20, 10, 5, 2, or $1 \mathrm{~mm}$. For larger measuring capacities, it is usually equipped with a small hand on a large dial, where one full turn of the large hour hand corresponds to 19 one small hour digit. The edge of the plate is generally equipped with two markers that can be adjusted in a position which states the upper and lower limits of the tolerance area of a product to be inspected. In addition, the scale dial can be rotated to set the zero position when the measurement starts [7-8].

When in use, the indicator dial is usually mounted on a stand as shown in Figure 2. The sensor height is adjusted to the nominal height/base size of the product to be dimensionally checked with the help of a block gauge. After the two limit marks on the dial indicator are positioned according to the tolerance area of the product, it is easy to check the geometric quality of the product [7-8].

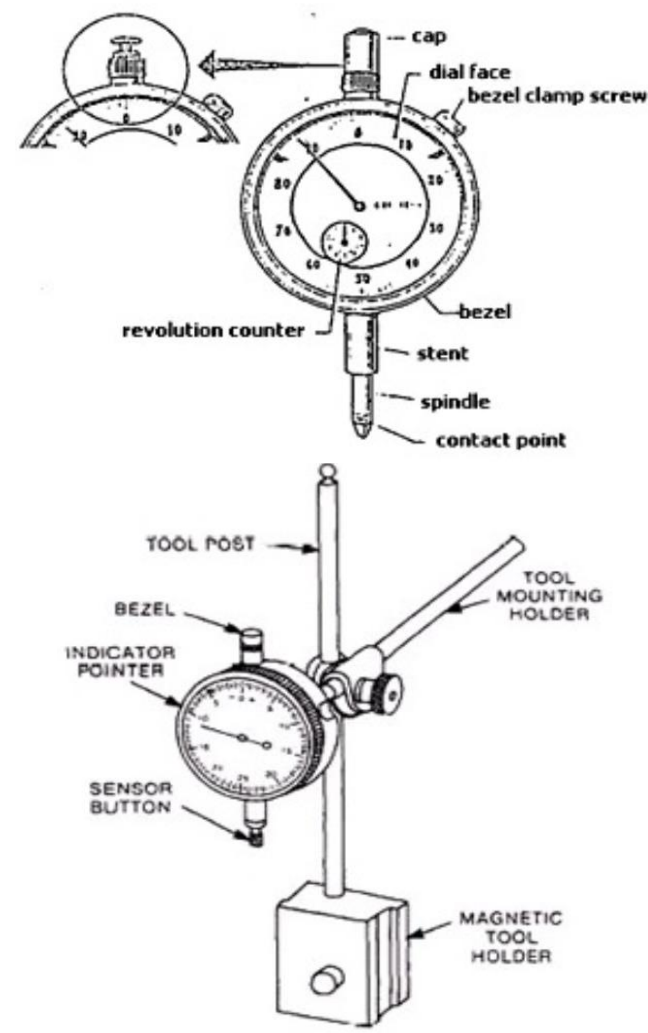

Figure 2: Use of dial indicator in measurement [7-8].

\subsection{Dial Indicator Calibration}

The calibration is an activity to do periodically by comparing standard quantities between measuring instruments and tester that is in accordance with the measuring instrument [9]. In the implementation of calibration, there is often an uneven coverage value, which is called the uncertainty value [1]. There are some methods to evaluate an uncertain for a dial indicator calibration. Lui et al. (2016) [10] conducted the evaluation of uncertain the effects of error sources calibration to estimate the corresponding standard uncertainties and sensitivity coefficients used laser interferometer. They calculated the combination standard uncertainty and effective degrees of freedom. Hermann \& Rudas (2016) [11] did study on the instrument measurement uncertainty to do the geometric measurement covering different features in the manufacturing industry. More, Hermann (2006) [12] conducted calibration system based computerization to analysis the confidence limits for the uncertainty.

According to [13], the procedure to analysis uncertainty is: (a) the calibration process identify to explain technical information and the test setup, reference standard, (b) defines the total error in the value of a quantity in terms of all relevant measurement process, (c) identify uncertainly sources of errors and probability distributions, (d) compute the correlation standard combined uncertainty and (e) the uncertain expand, which consider a larger fraction of measurement and value distribution, compared to the combined uncertainty. 


\subsection{EXPERIMENTAL METHOD}

This research was conducted at the Central for Material and Technical Products (B4T), by understanding the calibration method according to the JIS B 7503: 2017 standard for calibration of Dial Indicators. When performing a calibration, it is best to use the most recent standards.

This calibration method was used the procedure to calibrate the dial indicator with a measuring range of $0-25 \mathrm{~mm}$ and $0-50$ $\mathrm{mm}$ with a resolution of $0.01 \mathrm{~mm} 0.002 \mathrm{~mm}$ and $0.001 \mathrm{~mm}$.

The tools and materials used to calibrate the Dial Indicator, namely:

1. Calibration Tester No. 170-042, Serial Number: 9195, with

$0.001 \mathrm{~mm}$ accuracy and certificates, as shown in Figure 3.

2. Dial Indicator

3. Gauge Block Individual: $5 \mathrm{~mm}, 10 \mathrm{~mm}, 20 \mathrm{~mm}$.

4. Thermo hygrograph

5. Tissue

6. Fuel wash / alcohol

7. A set of instrument screw drivers

8. Lap

9. Work sheet

10. Calculator

After all the tools and materials were available, the next step of the calibration preparation process, which was:

1. Check in advance, whether the dial was functioning properly

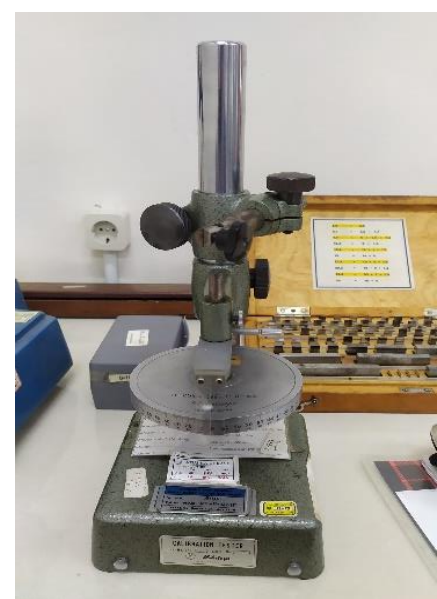

Figure 3: Calibration tester

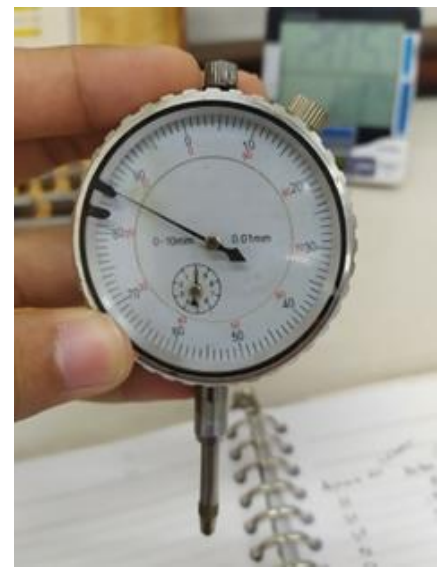

Figure 4: Dial indicator check or not by pressing the end of the sensor, whether it was functioning or not, as shown in Figure 4.

2. Lean the dial from oil / lubricant and from dust or dirt.

3. Dry again using a cloth.

4. Clean the Calibration Tester also using a tissue, as well as the Gauge Block.

5. Make a condition of the Dial Indicator and Calibration Tester at a laboratory temperature of $21 \pm 1{ }^{\circ} \mathrm{C}$ and humidity of $55 \pm 5 \%$ for at least 24 hours until they have the same temperature and humidity as the temperature and humidity of the calibration laboratory.

6. Record the start date of the dial conditioning on the worksheet.

7. Record and identify the dial indicator to be calibrated on the worksheet.

8. Make sure the dial indicator was ready to be calibrated.

Furthermore, the calibration process steps were following: Place the dial indicator on the Calibration Tester holder in a vertical position, so that the measuring shaft dials just above the calibration tester axis shaft, as shown in Figure 5.

1. Before calibration, set the reading to the zero position on the dial indicator and calibration tester, as shown in Figure 6 and 7.

2. If a gauge block was added, at the maximum scale a calibration tester was added to the individual gauge block above the runway shaft.

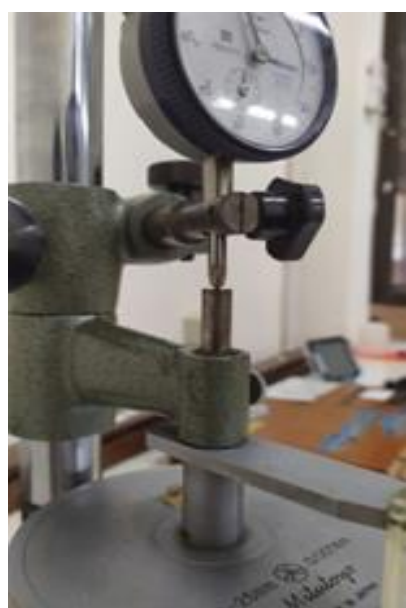

Figure 5: Dial indicator mounted on the calibration tester holder

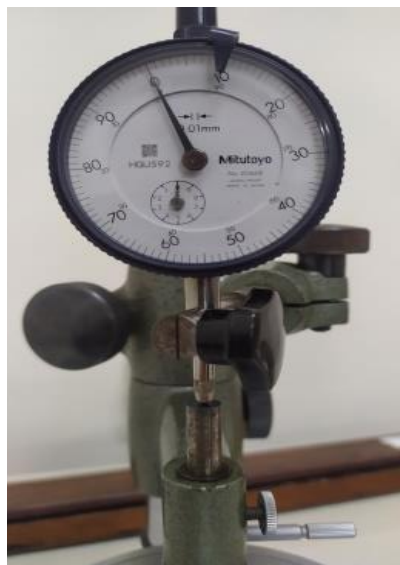

Figure 6: The position of the needle on the dial indicator is zero 


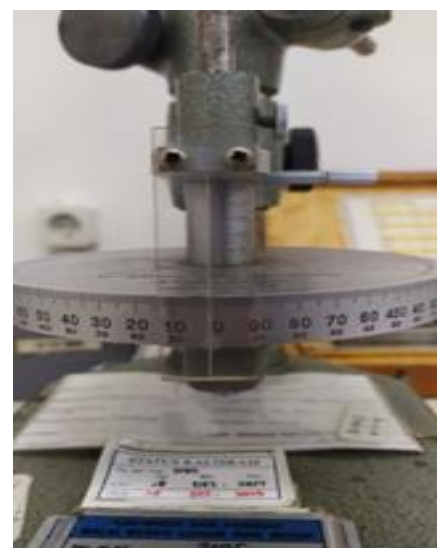

Figure 7: The reading position in calibration tester of 0

3. Calibration was performed on each $1 / 10$ cycle after $1 / 10$ cycle, continuing up to 2 rounds. Then proceed with each $1 / 2$ cycle after $1 / 2$ cycles, continuing up to 5 rounds. And continued again at each of 1 round after 1 round, continuing to rise until the maximum round dial. Likewise for the step down, with the same points on the step up.

4. Perform the calibration by moving the standard dish until the needle on the dial indicator showed the exactly of position that was observing. And read the appointment of the calibration tester perpendicularly in front of our observations and note the results obtained.

5. Perform data collection for the observation position up and when the observation down as many as three series of observations.

6. Record the reading of the dial indicator and the standard on the worksheet.

7. Calculate the correction value of the effect of the expansion coefficient and the effect of the temperature and the actual average value of each point of observation when the pressure / position were up and down.

8. Calculate the error of each observation from each poin when the position was up and down.

9. Create a revolution graph (revolution) versus indicator error (Indication Error), with rotation as the $\mathrm{x}$-axis and indicator error as the y-axis.

10. From the graph, got an error indicator at: $1 / 10$ round (or also called adjacent error), $1 / 2$ round, 1 round, 2 rounds.

11. For adjacent errors or indicator errors on $1 / 10$ of the round, take the greatest value from the difference between adjacent indicator errors.

12. Evaluation of the calculation of errors with the requirements table in JIS B 7503: 1997.

\subsection{RESULT AND DISCUSSION}

In a process of calibrating a measuring instrument, it is influenced by several factors such as the uncertainty of the measuring instrument, the uncertainty of the calibration tool, the standard deviation, changing in temperature, general uncertainty and the combined uncertainty. Therefore, from all the values of these factors, the uncertainty value can be obtained. Based on the ASTM standard, the uncertainty value allowed was not more than 1 , so the permitted value must be below 1\% and not exceeding the CMC (Calibration and Measurement Capability).
The CMC values were obtained through calculations with values from measuring instruments that have been tested at institutions that have higher standards. This measurement aims to equate standards with the rest of the world. Meanwhile, the purpose of this calibration of measuring instruments is to provide safety and quality of the products used. The calibration certificate from a device at the company is also very functioning to guarantee the quality of the products it produces.

The observation data result of calibration test for loading up and down on the tester can be seen in Table 1-3.

\subsection{Calculation}

1. Results of corrections to the coefficient and effect of temperature after measurement

$$
C=L(1+\alpha \Delta T)
$$

Where the value is:

$$
\begin{aligned}
& \mathrm{L} \quad=10\left(X_{0.01 \mathrm{~mm}}\right) \\
& \alpha=1+10^{-6} /{ }^{\circ} \mathrm{C} \\
& \Delta \mathrm{T} \quad=20.3-20.2=0.1
\end{aligned}
$$

2. Actual average value

$$
\begin{array}{ll}
\bar{L}=\frac{\sum L i}{n} & \\
& \mathrm{Li} \quad=98,98,98 \\
& \mathrm{n} \quad=10 \\
& \bar{L}=\frac{98+98+98 / 3}{10} \\
& \bar{L}=\frac{98}{10}=9.80 \quad(\times 0.01 \mathrm{~mm})
\end{array}
$$

Table 1: Observation data 1, loading up and down

\begin{tabular}{ccc}
\hline $\begin{array}{c}\text { Numbers on dial } \\
(\mathrm{mm})\end{array}$ & \multicolumn{2}{c}{ Figures on the Tester } \\
Load Up $(\mathrm{mm})$ & Load Down $(\mathrm{mm})$ \\
\hline 10 & 98 & 97 \\
20 & 196 & 195 \\
30 & 297 & 293 \\
40 & 397 & 392 \\
50 & 498 & 495 \\
60 & 596 & 598 \\
70 & 697 & 695 \\
80 & 799 & 797 \\
90 & 901 & 898 \\
100 & 1002 & 1001 \\
110 & 1098 & 1097 \\
120 & 1199 & 1197 \\
130 & 1299 & 1298 \\
140 & 1399 & 1396 \\
150 & 1499 & 1498 \\
160 & 1602 & 1603 \\
170 & 1706 & 1704 \\
180 & 1806 & 1803 \\
190 & 1906 & 1907 \\
200 & 2004 & 2004 \\
250 & 2502 & 2501 \\
300 & 3009 & 3008 \\
350 & 3513 & 3510 \\
400 & 4018 & 4017 \\
450 & 4512 & 4512 \\
500 & 5017 & 5017 \\
600 & 6019 & 6021 \\
700 & 7026 & 7027 \\
800 & 8020 & 8020 \\
900 & 9006 & 9005 \\
1000 & 10004 & 10004 \\
& & \\
\hline
\end{tabular}


Table 2: Observation data 2, loading up and down

\begin{tabular}{|c|c|c|}
\hline \multirow{2}{*}{$\begin{array}{l}\text { Numbers on dial } \\
(\mathrm{mm})\end{array}$} & \multicolumn{2}{|c|}{ Figures on the Tester } \\
\hline & Load Up (mm) & Load Down (mm) \\
\hline 10 & 98 & 97 \\
\hline 20 & 191 & 188 \\
\hline 30 & 289 & 287 \\
\hline 40 & 390 & 389 \\
\hline 50 & 491 & 486 \\
\hline 60 & 593 & 589 \\
\hline 70 & 691 & 689 \\
\hline 80 & 792 & 790 \\
\hline 90 & 894 & 891 \\
\hline 100 & 993 & 990 \\
\hline 110 & 1095 & 1095 \\
\hline 120 & 1192 & 1190 \\
\hline 130 & 1293 & 1290 \\
\hline 140 & 1395 & 1391 \\
\hline 150 & 1493 & 1491 \\
\hline 160 & 1594 & 1593 \\
\hline 170 & 1700 & 1698 \\
\hline 180 & 1801 & 1798 \\
\hline 190 & 1900 & 1899 \\
\hline 200 & 1999 & 1999 \\
\hline 250 & 2497 & 2496 \\
\hline 300 & 3000 & 2996 \\
\hline 350 & 3505 & 3502 \\
\hline 400 & 4007 & 4006 \\
\hline 450 & 4511 & 4508 \\
\hline 500 & 5006 & 5005 \\
\hline 600 & 6008 & 6009 \\
\hline 700 & 7013 & 7013 \\
\hline 800 & 8016 & 8016 \\
\hline 900 & 8995 & 8993 \\
\hline 1000 & 10001 & 10003 \\
\hline
\end{tabular}

Table 3: Observation data 3, loading up and down

\begin{tabular}{|c|c|c|}
\hline \multirow{2}{*}{$\begin{array}{c}\text { Numbers on dial } \\
(\mathrm{mm})\end{array}$} & \multicolumn{2}{|c|}{ Numbers on tester } \\
\cline { 2 - 3 } & Load up $(\mathrm{mm})$ & Load down $(\mathrm{mm})$ \\
\hline 10 & 98 & 97 \\
30 & 197 & 196 \\
40 & 297 & 295 \\
50 & 398 & 398 \\
60 & 498 & 495 \\
70 & 598 & 594 \\
80 & 702 & 698 \\
90 & 800 & 798 \\
100 & 902 & 898 \\
110 & 1001 & 997 \\
120 & 1098 & 1096 \\
130 & 1200 & 1199 \\
140 & 1301 & 1298 \\
150 & 1401 & 1397 \\
160 & 1503 & 1500 \\
170 & 1606 & 1605 \\
180 & 1709 & 1708 \\
190 & 1806 & 1803 \\
200 & 1907 & 1905 \\
250 & 2004 & 2003 \\
300 & 2502 & 2502 \\
350 & 3009 & 3009 \\
400 & 3514 & 3511 \\
450 & 4018 & 4015 \\
500 & 4512 & 4509 \\
600 & 5019 & 5018 \\
700 & 6021 & 6020 \\
800 & 7026 & 7027 \\
900 & 8018 & 8019 \\
1000 & 9005 & 9006 \\
& 10003 & 10003 \\
\hline
\end{tabular}

3. Observation error

$$
\begin{aligned}
& \text { Error }(E)=L-\bar{L} \\
& \begin{array}{ll}
\mathrm{L} & =10(\times 0.01 \mathrm{~mm}) \\
\bar{L} & =9.80(\times 0.01 \mathrm{~mm})
\end{array} \\
& \text { Error }(E)=10-9.80 \\
& \text { Error }(E)=2.00(\times 0.001 \mathrm{~mm})
\end{aligned}
$$

4. Retrace error value

$$
\text { Retrace }=E_{\max }-E_{\min }
$$

Retrace $=3.00-2.00(\times 0.001 \mathrm{~mm})$

Retrace $=1.00(\times 0.001 \mathrm{~mm})$

5. Repeatability

$$
\begin{aligned}
& b=L_{\max }-L_{\min } \\
& b=1002.05-993.04 \\
& b=0.90(\times 0.01 \mathrm{~mm})
\end{aligned}
$$

Based on the testing that has been done, the following results were obtained:

1. Calculation of the value of uncertainty

a. On the calibration tool 95\% confidence level Coverage factor $\mathrm{k}$ (assumption) $=2$

- Dial calibration tester, uncertainty of certificate $(\mathrm{Ub} 1)=0.75000 \times 0.001 \mathrm{~mm}$

b. Readability

$$
\begin{aligned}
\mathrm{Ub} 2 & =(0.5 / 1.73205) \\
& =0.2886751 \times 0.001 \mathrm{~mm}
\end{aligned}
$$

c. Difference in expansion coefficient

$$
\begin{aligned}
\text { Ub3 } & =(2 \times 10-6 / 1.73205) \times 0.25000 \\
& =0.0300000 \times 0.001 \mathrm{~mm}
\end{aligned}
$$

d. Difference in temperature between standa and dial indicator

$$
\begin{aligned}
\text { Ub4 } & =(0.1 / 1.73205) \times 0.2875 \\
& =0.0165988 \times 0.001 \mathrm{~mm}
\end{aligned}
$$

e. Standard Drift

$$
\begin{aligned}
\text { Ub5 } & =(5 \times(0.05+0.5 \mathrm{e}-6 . \mathrm{L})) / 1.73205 \\
& =0.1443737 \times 0.001 \mathrm{~mm}
\end{aligned}
$$

f. Targeting error

$$
\begin{aligned}
\text { Ub6 } & =5 / 1.73205 \\
& =2.8867513 \times 0.001 \mathrm{~mm}
\end{aligned}
$$

g. Geometric

$$
\begin{aligned}
\mathrm{Ub} 7 & =5 / 1.73205 \\
& =2.8867513 \times 0.001 \mathrm{~mm}
\end{aligned}
$$

h. Deviation Standard

$0.16330 \times 0.001 \mathrm{~mm}$

i. Combined uncertainty (uc)

$(\text { Tipe } A)^{\wedge} 2+(\text { Tipe } B)^{\wedge} 2=4.1666756 \times 0.001 \mathrm{~mm}$

j. Uncertainty expanded (U95)

$\begin{aligned} \text { U95 } & =\mathrm{k} \times \text { uc } \\ \text { U95 } & =2 \times 4.1666756 \times 0.001 \mathrm{~mm} \\ \text { U95 } & =8.3333512 \times 0.001 \mathrm{~mm} \\ \text { U95 } & =8.33 \times 0.001 \mathrm{~mm} \\ \text { U95 } & =0.83 \times 0.01 \mathrm{~mm}\end{aligned}$




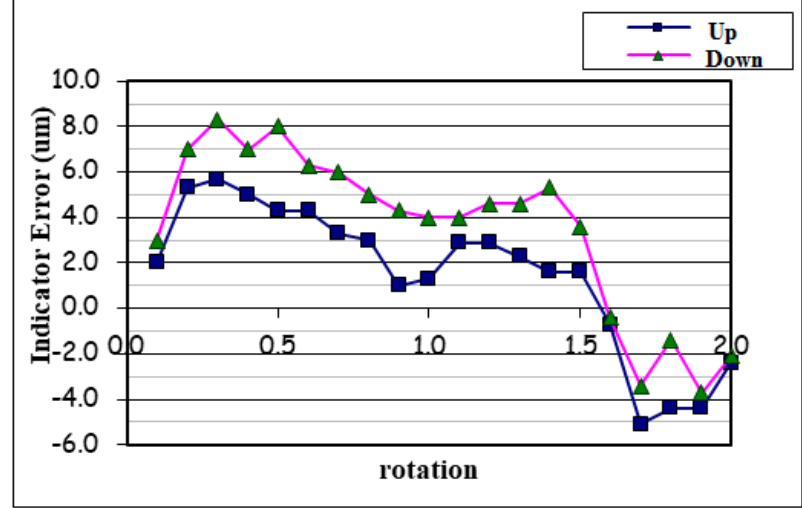

Figure 8: Graph of indicator error versus rotation/round

From the round graph vs error indicator, at the beginning, the load rises or falls, there was no significant difference (close to), likewise, at the second measurement point. However, when the calibration process was continued there was a significant difference in the rising and falling loads. When the calibration process enters the last points of the calibration process, the values obtained begin to have a slight difference, even at the last 5 points and also the highest point of the indicator dial, the values obtained were exactly the same. This may be occurred due to several factors, such as the main factor of accuracy of the tool, the accuracy of comparator or standard tool that becomes a reference during the calibration process. As mentioned earlier, that standard tool also has its own uncertainty value. Furthermore, that was due to the accuracy of the calibration operator. The ability of the operator to read numbers on a standard device (in this case the calibration tester) and the numbers on the indicator dial could be also factors that determine the error of the calibration process.

\subsection{CONCLUSION}

Based on the calibrations that have been made, several conclusions can also be drawn, which is:

- Calibrationn is a standard procedure in factories/companies, especially those engaged in production, because it can control the quality of the equipment used, and can show whether the tool is feasible or not to be used.

- The obstacle experienced during dial Indicator calibration is the concentration of the operator performing the calibration, which can affect the results of readings on the dial and on standard equipment. There are also some cases where the measuring capacity and reference standards are not suitable when trying to calibrate.
- The standard used in the dial indicator calibration is JIS B 7503: 1997 and the latest is JIS B 7503: 2017.

\section{REFERENCES}

[1] Sufyani, R. \& Hartanto, D. (2016). Analisis prosedur kalibrasi dalam menentukan nilai ketidak-pastian pada dial indikator berdasarkan JIS B 7503, Isu Teknologi STT Mandala, 11(1), 67-80.

[2] ISO/IEC 17025, General requirements for the competence of testing and calibration laboratories.

[3] National Accreditation Body of Indonesia (Komite Akreditasi Nasional-KAN).

[4] Amani, N. \& Arief, D.S. (2015). Kalibrasi jangka sorong nonius (vernier calliper) berdasarkan Standar JIS B 7507 di laboratorium pengukuran teknik mesin universitas riau, Jurnal JOM FTEKNIK, 2(2).

[5] Zulfebri \& Arief, D.S. (2015). Kalibrasi jangka sorong jam ukur (dial calliper) menggunakan metode standar JIS B 7507 - 1993 di laboratorium pengukuran teknik mesin universitas riau, Jurnal JOM FTEKNIK, 2(2).

[6] Kurnia, A. \& Arief, D.S. (2015). Kalibrasi mikrometer sekrup eksternal dengan mengacu pada standar JIS B 7502 - 1994 di laboratorium pengukuran teknik mesin universitas riau, Jurnal JOM FTEKNIK, 2(2).

[7] Taufiq, R. 2006. Spesifikasi, Metrologi \& Kontrol Kualitas Geometrik 1. Bandung: ITB.

[8] Taufiq, R. 2006. Spesifikasi, Metrologi \& Kontrol Kualitas Geometrik 2. Bandung: ITB.

[9] Arief, D.S., Badri, M., Dalil, M., Reforiandi, A., \& Permana, A. (2020). Calibration of vickers hardness test in pt. tenaris seamless pipe Indonesia jaya cilegon using standar blok, Journal of Ocean, Mechanical And Aerospace -Science and Engineering-, 64(3), 81-87. doi:10.36842/jomase.v64i3.203.

[10] Lui, P.K.W., Liou, H.C., Chang, W.C. \& Huang, H.C. (2015). Uncertainty evaluation of the calibration of dial indicator calibrators by laser interferometer, NCSLI Measure, 10(4), 20-23.

[11] Hermann, G. \& Rudas, I.J. (2016). Form and length measuring equipments and gauges for the manufacturing industry, IEEE 20th Jubilee International Conference on Intelligent Engineering Systems (INES), 81-84.

[12] Hermann, G. (2006). Computerised dial gauge calibration system, IEEE International Conference on Computational Cybernetics, 1-3, doi: 10.1109/ICCCYB.2006.305737.

[13] Upasani, K.A \& Patkar, S. (2015). Determining measurement uncertainty parameters for calibration processes, The International Journal of Engineering and Science (IJES), 4(11), 2319-1805. 